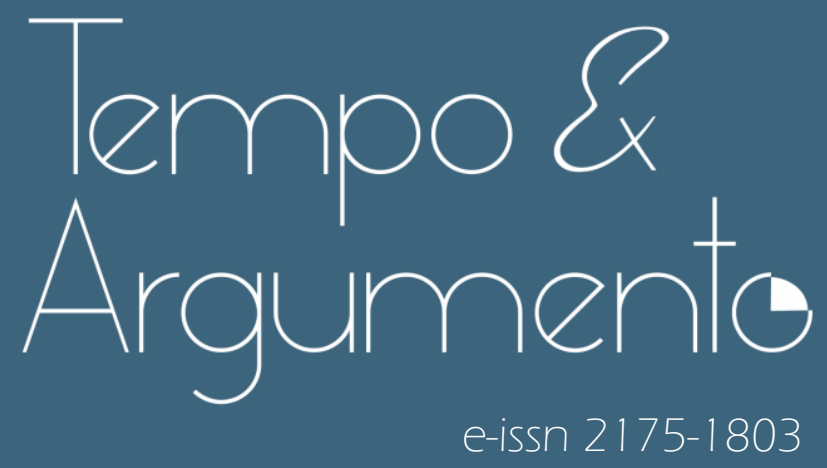

\title{
Un archipiélago estatal para las infancias populares argentinas (1890-1919)
}

Resenha da obra:

FREIDENRAIJ, Claudia. La niñez desviada: La tutela estatal de niños pobres, huérfanos y delincuentes. Buenos Aires 1890-1919. Buenos Aires: Editorial Biblos, 2020, 302 pp.

- Susana Sosenski

Doctora en Historia, Investigadora del Instituto de Investigaciones Históricas de la Universidad Nacional Autónoma de México (UNAM).

Ciudad de México - MÉXICO

investigadores/sosenski.html

sosenski@gmail.com

(D) orcid.org/0000-0001-7073-3531

Para citar esta resenha:

FREIDENRAIJ, Claudia. La niñez desviada: La tutela estatal de niños pobres, huérfanos y delincuentes. Buenos Aires 1890-1919. Buenos Aires: Editorial Biblos, 2020, 302 pp. Resenha de: SOSENSKI, Susana. Un archipiélago estatal para las infancias populares argentinas (1890-1919). Revista Tempo e Argumento,

Florianópolis, v. 13, n. 32, e0402. jan./abr. 2021.

doi http://dx.doi.org/10.5965/2175180313322021e0402

Recebido: $12 / 10 / 2020$

Aprovado: 03/02/2021 


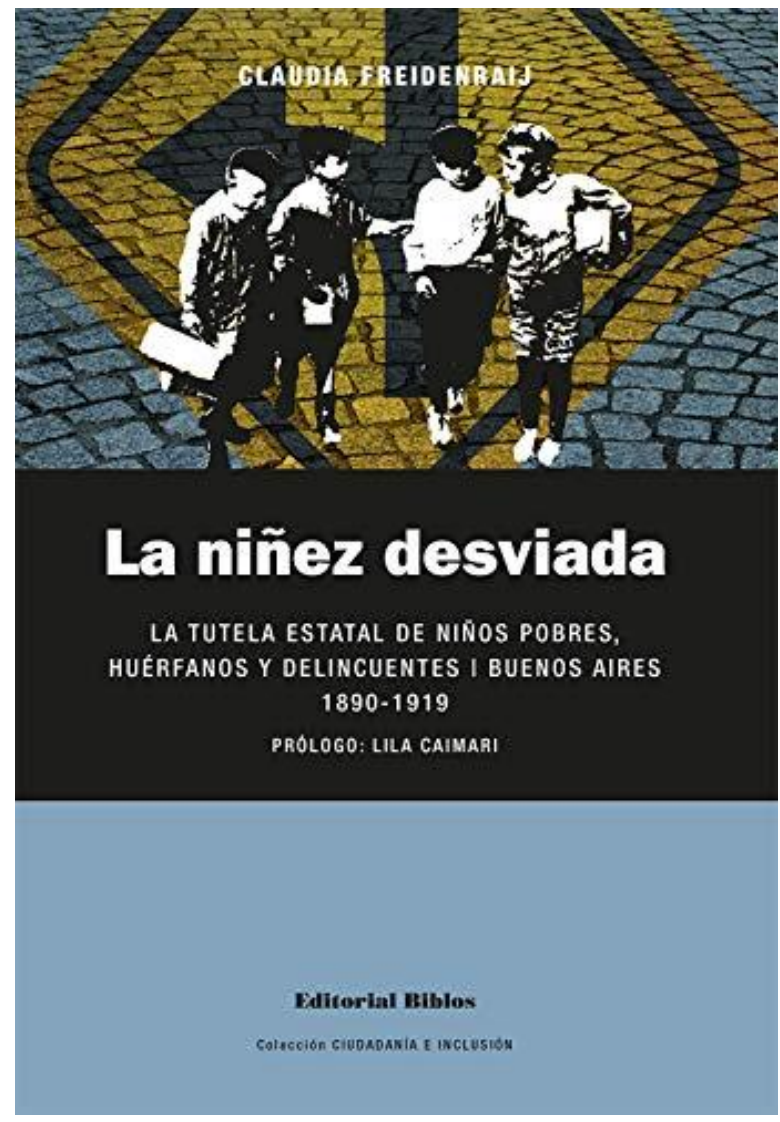

\section{Resenha da obra:}

FREIDENRAIJ, Claudia. La niñez desviada: La tutela estatal de niños pobres, huérfanos y delincuentes. Buenos Aires 1890-1919. Buenos Aires: Editorial Biblos, 2020, 302 pp.

La niñez desviada: La tutela estatal de niños pobres, huérfanos y delincuentes. Buenos Aires 1890-1919 es una investigación minuciosa y profunda realizada por la historiadora argentina Claudia Freidenraij sobre una época en la que "las calles [de tierra] de Buenos Aires estaban salpicadas de niños" (p.13). Enmarcado en el periodo que va desde 1890 a 1919 este libro analiza los intersticios de las intervenciones públicas que recayeron en la capital argentina sobre los niños pobres, huérfanos, infractores, delincuentes pero especialmente de los sectores trabajadores, en un momento clave de transformaciones urbanas.

Aquí no sólo reconstruye y analiza el complejo articulado de politicas de castigo y represión de actividades y hábitos de los niños de las clases trabajadoras urbanas previo a lo que se consideraría una "justicia para menores," sino también las formas en que se estereotiparon esas prácticas construyendo categorías jerarquizadoras y segregacionistas sobre estos sectores etarios y poblacionales. Bajo la etiqueta criminalizante y clasista de "minoridad", las élites morales, constituidas en parte por una constelación de especialistas, colocaron sobre los niños de las clases trabajadoras un conjunto de etiquetas que no sólo inventarían categorías infantiles sino que asociarían prácticas de la infancia pobre con la desviación, la inmoralidad, el abandono y la delincuencia.

A partir de un enfoque que se nutre y forma parte de la historia social, de la historia del delito y la justicia, así como de la historia de las infancias, la autora 
consigue el relevamiento y análisis de un amplio corpus documental, fotografías, diarios y revistas, memorias de justicia, legislación, fuentes policiales, autobiografías, crónicas urbanas, cuentos, informes médico-legales. Con estas fuentes Freidenraij va desagregando cada uno de los adjetivos, cada una de las prácticas, para estudiarlos separadamente y mostrar cómo la construcción discursiva de la minoridad, el abandono o la delincuencia, vista en espejo, devuelve una imagen que permite ver las ideologías clasistas y los prejuicios de las "elites morales" hacia las infancias pobres urbanas.

La presencia de niños de los sectores populares en el espacio urbano, como muestra con detalle Freidenraj, causó alarma e incomodidad en quienes pretendían un ilusorio orden urbano. Para contener y minimizar las imágenes de niños efectuando todo tipo de labores o transgrediendo constantemente las múltiples normativas, se construyó, para usar las palabras de la autora, un archipiélago penal y asistencial de establecimientos, agencias estatales e instituciones particulares, cuyos engranajes operaron en conjunto, en un concierto de voces e intervenciones que oscilaron más en discordancia que en armonía, más hacia la represión que hacia el amparo.

El libro se concentra en niños mayoritariamente varones, porque hacia ellos se orientaron las políticas criminológicas del periodo de estudio y porque constituían el 82 por ciento de los aprehendidos (p. 108). A través de una lúcida escritura y análisis, la autora acompaña a esos centenares de niños en sus trayectos y circulaciones. Su intención es no dejarlos solos en algún momento. De tal forma, frente al histórico emplazamiento como "niños abandonados" que han sufrido, ella se decide por tomar una postura vinculante de cuidado, de atención, de conexión con sus situaciones y de búsqueda de entendimiento sobre cómo ha sido que han llegado a las puertas de las instituciones de control social. Así, advierte su vida en los conventillos, sus intermitencias escolares, los sigue a sus andanzas en calles, veredas y plazas, presencia sus juegos, escucha sus malas palabras y sus risas, los ve subirse colgados a los tranvías. En las líneas de este texto es posible escuchar la sonoridad que producían los niños en la calle. Pero el libro muestra, cómo al terminar el día no todos aquellos niños y muchachitos podían volver a sus casas o a sus andanzas. En tanto caía sobre 
ellos un amplio abanico de disposiciones de corte jurídico y se consideraban parte de un "problema social" que había que combatir, sus actividades estuvieron siempre al borde de ser delictivas, irregulares o "predelictivas" en tanto pertenecían a un sector social sobre el cual el Estado buscaba intervenir (p. 285). La institucionalización, por lo tanto, aparece siempre acechante al otro lado de la esquina; esto no hace que la autora los pierda de vista: los sigue a sus comparecencias ante la justicia, hasta los interiores de las instituciones, como si de un estudio etnográfico se tratara, escucha lo que los agentes del estado piensan sobre ellos, lo que escriben los jueces de menores, advierte el tratamiento que se les da a los cuerpos infantiles y luego articula todas estas observaciones en un estudio puntilloso de las estructuras de control y de construcción del "peligro infantil".

El libro disecciona la anatomía de las prácticas de los agentes encargados o interesados en la "corrección" de esa infancia: jueces, intelectuales, defensores de menores, médicos, abogados. La policía aparece especialmente protagónica, preocupada por lo que considera una ocupación anárquica de la ciudad por los niños: no le gusta como juegan, cómo se relacionan, cómo se comportan (p.115), considera sus actividades siempre sospechosas, elabora catálogos de cada vez más crecientes normativas, porque los niños en el espacio público, si lo ocupan autónomamente, incomodan, en cualquier sitio, en Argentina, en México, en Brasil, en América Latina.

Los vaivenes que sufre la justicia para menores en los primeros años de su implementación en Buenos Aires son una respuesta, explica la autora, a la alarma social frente a las condiciones antihigiénicas y de hacinamiento que sufrían los niños en las cárceles con adultos delincuentes o detenidos. consideraciones de orden moral e higiénico fueron las que impulsaron a las autoridades a construir instituciones de castigo infantil diferenciadas del mundo adulto, que en un inicio serían de corte religioso y luego laboral. El texto subraya cómo las violencias físicas contra los niños y adolescentes se implementaron también como terapéuticas correccionales por los encargados del orden carcelario. Pero, como la sociología, la antropología y la historia de la infancia ya han apuntado, los niños son actores sociales y siempre tienen respuestas 
imprevistas a los intentos de control que caen sobre ellos. Por eso, en este libro, aparecen también las resistencias infantiles a ese sistema lacerante de cuerpos y emociones. Aparecen entonces los niños como sujetos capaces de burlarse de las autoridades carcelarias, de ejercer su sexualidad dentro de los límites marcados por la prisión, por el encierro, por el género, organizando sociabilidades estructuradas a partir del lenguaje, de la risa, del juego.

El periodo que se trabaja en este libro se inscribe en un momento de despunte de la transnacionalización de las ideas de infancia. En 1916 se reúnen los "especialistas", esas élites morales, especialmente de los saberes médicopedagógicos, en la ciudad de Buenos Aires, en lo que sería el I Congreso Panamericano del Niño, para discutir las acciones necesarias para higienizar, moralizar y escolarizar a la población infantil del continente. Los discursos estigmatizantes, las políticas sancionadoras y la persecución de las prácticas de los hijos de las clases trabajadoras se posicionan como uno de los nodos en las iniciativas en favor de la infancia de los países de la región.

Por todo lo anterior, este libro, si bien se dedica al caso argentino, también puede leerse en clave latinoamericana para vislumbrar los puntos en común con experiencias acaecidas en otras latitudes: las sociabilidades infantiles en conventillos, vecindades o inquilinatos y sus porosas fronteras con la calle, fabricada como espacio peligroso, la construcción de la figura del incorregible, las colocaciones de los niños en hogares y talleres, la criminalización constante de las prácticas cotidianas, la construcción de un andamiaje de leyes y normas para el control de la infancia en sus tránsitos por los rumbos de la ciudad, o la laborterapia como método de regeneración de los llamados menores delincuentes. Los niños argentinos no son los niños indígenas del México del porfiriato y de la revolución, tampoco los que venden diarios en Bogotá al iniciar el siglo, o los niños negros que trabajan en las calles de Sao Paulo. Sin embargo, coinciden con ellos temporalmente y sufren políticas que han cruzado las fronteras nacionales en forma de ponencias en congresos, de publicaciones en revistas médicas o criminológicas, en editoriales y noticias en la prensa. Así, terminan siendo depositarios de formas hegemónicas de concebir a las infancias 
populares acusadas de peligrosas, inmorales y antihigiénicas, discursos que justifican la obligatoriedad de que el Estado controle sus prácticas.

Los seis capítulos de este libro recuperan largos años de avances en la historia de las infancias en América Latina y proponen caminos novedosos para interpretar la minoridad, la categoría etaria, la historia de la criminalidad y el delito, y su vínculo con la historia social de la infancia. Es un libro propositivo e inteligente que da cuenta de la madurez y la plenitud en la que se encuentra este campo historiográfico en Latinoamérica. 